\title{
Pengaruh Latihan Vokal terhadap Perubahan Kemampuan Menelan pada Pasien Stroke Infark di Ruang Cempaka Rumah Sakit Umum Daerah Dr. Slamet Garut Tahun 2015
}

\author{
Zahara Farhan \& Sulastini \\ STIKes Karsa Husada Garut
}

\begin{abstract}
Stroke infarction occurs due to disturbances in neurological system such as loss of motor function, sensibility and loss of consciousness due to tissue death due to oxygen supply to the brain is disrupted. Manifestations are impaired ability to swallow. One of the interventions to address the impaired ability to swallow, namely vokal exercises. This study aimed to influence vokal exercises to changes in swallow ability stroke infarction in room Cempaka dr. Slamet Garut Hospital. This study was conducted in May - June 2015 in room Cempak dr. Slamet Garut Hospital using a quasi experimental design. The sampling technique used purposive sample of 10 respondent. Date collection used observation checklist sheet and direct observations of researchers. The hypothesis test usedis Mann-Whitney. Hypothesis test results showed there are significant ( $\mathrm{p}$ 0.004) vokal exercises to changes in the patient's ability to swallow infarction stroke at Cempaka Room dr. Slamet Garut Hospital with a meanof the ability to swallow priorto the vokal exercises of 3.00 and after the vokal exercises of 5.50.The results could be used as reference material and consideration for physicians and nurses in dealing with stroke patients with impaired myocardial swallow function by doing vokal exercises.
\end{abstract}

Keywords : Stroke Infarction, Vokal Exercise, Ability Swallow

\begin{abstract}
Abstrak. Stroke infak terjadi karena gangguan pada sistem neurologi berupa kehilangan fungsi motorik, sensibilitas dan kehilangan kesadaran karena kematian jaringan akibat suplai oksigen ke otak terganggu. Berdasarkan data dari rekam medik RSUD dr.Slamet Garut tahun 2014, jumlah penderita stroke infark sebanyak 1.254 orang. Manifestasi yang sering terjadi adalah gangguan kemampuan menelan. Salah satu intervensi untuk mengatasi gangguan kemampuan menelan yaitu latihan vokal. Tujuan penelitian mengetahui pengaruh latihan vokal terhadap perubahan kemampuan menelan stroke infark di ruang Cempaka RSUD dr. Slamet Garut. Penelitian ini dilakukan pada bulan Mei-Juni 2015 di ruang Cempaka RSUD dr. Slamet Garut dengan menggunakan desain kuasi eksperimen. Teknik pengambilan sampel menggunakan purposive samplingsebanyak 10 responden.Pengumpulan data menggunakan lembar ceklis observasi dan pengamatan langsung peneliti. Uji hipotesis dengan menggunakan Wilcoxon. Hasil uji hipotesis terdapat pengaruh (p0,004) latihan vokal terhadap perubahan kemampuan menelan pada pasien stroke infark di Ruang Cempaka RSUD dr. Slamet Garut dengan nilai rerata kemampuan menelansebelum dilakukan latihan vokal sebesar 3,00 dan setelah dilakukan latihan vokal sebesar 5,50. Hasil penelitian ini dapat dijadikan sebagai bahan referensi dan pertimbangan bagi dokter dan perawat dalam menangani pasien stroke infark yang mengalami gangguan fungsi menelan dengan cara melakukan latihan vokal.
\end{abstract}

Kata Kunci : Stroke Infark, Latihan Vokal, Kemampuan Menelan

\section{A. PENDAHULUAN}

Berdasarkan data WHO, terdapat 15 juta orang di dunia menderita stroke setiap tahunnya dengan jumlah kematian sebanyak 5 juta orang pertahun dan sebagian lainnya mengalami kecacatan permanen. Penyakit stroke di Indonesia merupakan penyebab kematian utama. Hasil Riset Kesehatan Dasar (Riskesdas) Kementerian RI tahun 2013 terjadi peningkatan prevalensi stroke di Indonesia dari 8,3 juta jiwa pada tahun 2007 menjadi 12,1 juta jiwa pada tahun $2013^{1}$. Berdasarkan data dari Dinas Kesehatan Kabupaten Garut, penyakit stroke merupakan penyebab kematian utama dengan jumlah penderita sebanyak 1.340 orang selama satu tahun, termasuk di RSUD dr.Slamet Garut yang berjumlah sebanyak 1.254 orang.

Stroke yang disebabkan oleh perdarahan pada jaringan otak dan 
lapisan pembungkus otak disebut stroke hemoragik, sedangkan stroke yang disebabkan oleh adanya trombus atau emboli disebut stroke infark (Non Hemoragik) $^{3}$. Stroke infak mengakibatkan gangguan pada sistem neurologi berupa kehilangan fungsi motorik, sensibilitas dan kehilangan kesadaran karena kematian jaringan akibat suplai oksigen ke otak terganggu.

Manifestasi klinis yang muncul akibat dari stroke infark salah satunya penurunan kemampuan fungsi menelan. Menelan merupakan proses yang kompleks karena melibatkan beberapa fungsi saraf kranial. Gangguan menelan disebabkan oleh paresis atau kerusakan nervus fasialis, nervus trigeminus, nervus hipoglosus, nervus glossoparingeus, dan nervus vagus. Nervus-nervus tersebut berperan dalam proses mengunyah dan bicara. Adanya gangguan pada salah satu nervus tersebut maka akan berdampak pada keadekuatan fungsi menelan, mengunyah atau fungsi wicara $^{3}$. Timbulnya gangguan fungsi menelan dapat mengakibatkan terjadinya dehidrasi, malnutrisi, bahkan pneumonia akibat kerusakan katup epiglotis yang memungkinkan terjadinya aspirasi cairan atau makanan ke dalam saluran pernafasan.

Penatalaksanaan pasien yang mengalami gangguan fungsi menelan akibat stroke infark dapat dilakukan melalui terapi non farmakologi berupa terapi gabungan latihan dan kompensasi seperti memodifikasi diet dan latihan motorik oral. Latihan motorik oral bisa dilakukan dengan cara latihan vokal, terapi wicara, latihan mengunyah atau latihan menelan makanan. Latihan vokal adalah terapi rehabilitasi yang dilakukan dengan cara mengucapkan huruf vokal A, I, U, E, O. Tujuan latihan vokal untuk membiasakan lidah agar tidak kaku dan memperbaiki kekakuan saat berbicara, serta melatih fungsi saraf yang ada di sekitar rongga mulut. Teknik latihan vokal dapat dilakukan dengan mengucapkan huruf A, I, U, E, O dengan jelas dan lantang selama 3-5 menit sebanyak 3 kali sehari selama 1 minggu berturut-turut.

Beberapa hasil penelitian tentang pengaruh latihan menelan terhadap status fungsi menelan pada pasien stroke infark yang mengalami disfagia diperoleh hasil bahwa, nilai rata-rata kelompok yang diberi perlakuan latihan menelan 3 kali sehari setiap jam makan selama 6 hari berturut-turut mempunyai nilai yang lebih tinggi dibanding kelompok kontrol yang tidak diberi perlakuan, dengan p-value sebesar 0,02 yang mempunyai makna bahwa latihan menelan dapat meningkatkan status fungsi menelan pada pasien stroke infark yang mengalami disfagia.

Berdasarkan hasil studi pendahuluan yang dilakukan melalui wawancara dengan perawat di ruang penyakit saraf cempaka RSUD dr.Slamet Garut, sebagian besar pasien stroke mengalami gangguan dalam reflek menelan. Hal ini didukung oleh hasil observasi dimana dari 21 pasien stroke infark 14 orang mengalami gangguan menelan dan 4 orang terpasang alat bantu makan (Nasogastric Tube). Pemasangan NGT merupakan tindakan yang beresiko jika dilakukan tidak sesuai prosedur dan asupan makanannya terbatas hanya makanan cair saja. Selain itu juga pasien perlu dilatih untuk mengembalikan kemampuan menelan selama proses perawatan, karena penanganan yang tepat dalam pemberian asuhan keperawatan bisa mengurangi komplikasi akibat gangguan menelan. 


\section{B. RUMUSAN MASALAH}

Berdasarkan uraian dan fenomena di atas, maka rumusan masalah penelitian ini adalah "Adakah Pengaruh Latihan Vokal terhadap Perubahan Kemampuan Menelan pada Pasien Stroke Infark di Ruang Cempaka Rumah Sakit Umum Daerah dr.Slamet Garut tahun 2015?".

\section{TUJUAN PENELITIAN}

\section{Tujuan Umum}

Mengetahui pengaruh latihan vokal terhadap perubahan kemampuan menelan pasien stroke infak di ruang cempaka Rumah Sakit Umum Daerah dr.Slamet Garut tahun 2015.

\section{Tujuan Khusus}

1. Mengidentifikasi kemampuan menelan pasien stroke infark sebelum dan sesudah dilakukan latihan vokal.

2. Menganalisis pengaruh latihan vokal terhadap perubahan kemampuan menelan pada pasien stroke infark di ruang cempaka Rumah Sakit Umum Daerah dr.Slamet Garut tahun 2015.

\section{Kajian Pustaka dan Kerangka Pemikiran Penelitian}

\section{Konsep Dasar Stroke Infark}

1. Definisi Stroke Infark

Sroke infark adalah terganggunya sirkulasi serebral yang disebabkan oleh adanya penyumbatan pembuluh darah oleh trombus atau embolus yang mengakibatkan menurunnya suplai oksigen ke otak (hipoksia serebral) yang berdampak terhadap kematian jaringan otak.

2. Faktor Resiko Stroke Infark

Faktor resiko terjadinya stroke antara lain:

a. Hipertensi
Hipertensi dapat disebabkan oleh arterosklerosis pembuluh darah serebral sehingga mengalami penebalan dan degenerasi yang kemudian pecah dan menimbulkan perdarahan.

b. Penyakit Kardiovaskuler Penyakit arteri

koronaria, gagal jantung kongestif, dan hipertrofi ventrikel kiri menyebabkan penurunan Cardiac Output (CO) yang berdampak terganggunya perfusi darah ke otak (iskemia serebral).

a. Diabetes Melitus (DM) Komplikasi dari penyakit DM terjadinya mikrovaskularisasi dan aterosklerosis yang dapat mengakibatkan emboli dan menurunkan perfusi darah ke otak.

b. Merokok

Nikotin akan menyebabkan terjadinya timbunan plaque pada pembuluh darah sehingga memungkinkan terjadinya arteroklerosis yang mengakibatkan menurunnya suplai darah ke otak.

c. Alkoholik

Alkohol akan menyebabkan terjadinya aritmia jantung yang berdampak pada kelainan motilitas pembuluh darah sehingga terjadi emboli serebral.

d. Peningkatan Kolesterol Peningkatan kolesterol tubuh menyebabkan arteroklerosis dan terbentuknya emboli lemak sehingga terjadi penurunan suplai darah ke otak.

e. Obesitas

Individu obesitas 
memiliki kecenderungan peningkatan kadar kolesterol yang tinggi dan kecenderungan mengalami hipertensi yang berdampak terjadinya penurunan suplai darah ke otak.

f. Riwayat Keluarga Faktor genetik dalam keluarga disini bukan karena stroke bisa menurun lewat gen, melainkan resiko terjadinya strok karena faktor penyakit yang bisa menurun seperti hipertensi, DM, atau kelainan bawaan pada pembuluh darah.

g. Usia

Semakin bertambahnya usia resiko terjainya stroke semakin tinggi jika tidak bisa menjaga pola hidup sehat.

h. Stres Emosional.

Stres emosional merupakan salah satu penyebab terjadinya hipertensi yang mengakibatkan arterosklerosis pembuluh darah serebral.

3. Patofisiologi Stroke Infark (Non Hemoragik)

Otak sangat sensitif terhadap kondisi penurunan atau hilangnya suplai darah. Hipoksia dapat menyebabkan iskemik serebral karena tidak seperti jaringan pada bagian tubuh lain. Otak tidak bisa menggunakan metabolisme anaerob jika terjadi kekurangan oksigen atau glukosa. Otak diperfusi dengan jumlah yang cukup banyak dibanding organ lain yang kurang vital untuk mempertahankan metabolisme serebral. Iskemik jangka pendek dapat mengarah kepada penurunan sistem neurologis sementara atau Trancient Iskemik Attack (TIA). Jika aliran darah tidak diperbaiki, terjadi kerusakan yang tidak dapat diperbaiki pada jaringan otak atau infark dalam hitungan menit. Luasnya infark tergantung pada lokasi dan ukuran arteri yang tersumbat dan kekuatan sirkulasi kolateral ke area yang disuplai.

Iskemia dengan cepat bisa menggangu metabolisme. Kematian sel dan perubahan yang permanen dapat terjadi dalam waktu 3-10 menit. Tingkat oksigen dasar klien dan kemampuan mengonpensasi menetukan seberapa cepat perubahan yang tidak bisa diperbaiki akan terjadi. Tekanan perfusi serebral harus turun dua pertiga dibawah nilai normal (nilai tengah tekanan arterial sebanyak 50 $\mathrm{mmHg}$ atau dibawahnya dianggap nilai normal) sebelum otak tidak menerima aliran darah yang adekuat. Dalam waktu yang singkat, klien yang sudah kehilangan kompensasi autoregulasi akan mengalami manifestasi dari gangguan neurlogis. Penurunan perfusi serebral biasanya disebabkan oleh sumbatan yang terjadi, kemudian mengakibatkan iskemik pada jarigan otak yang mendapatkan suplai darah dari arteri yang terganggu dan karena adanya pembengkakan di jaringan sekelilingnya. Sel-sel di bagian tengah atau utama pada lokasi stroke akan mati dengan segera setelah kejadian stroke terjadi. Hal ini dikenal dengan istilah cedera sel-sel saraf primer (primary neuronal injury).

Beberapa proses reaksi biokimia akan terjdi dalam hitungan menit pada kondisi iskemik serebral. Reaksi-reaksi tersebut seperti neurotoksin, oksigen radikal bebas (oxygen free radicals), nitro ksigen (nitric oxide), dan glumatat (glutamate) akan dilepaskan. Asidosis lokal juga akan terbentuk, depolarisasi membran akan terjadi, sehingga hasilnya akan terjadi edema sitotoksik dan kematian sel. Hal ini dikenal dengan perlukaan sel-sel saraf sekunder (scondary neuronal injury). 
Bagian yang membengkak setelah iskemik bisa mengarah kepada penurunan fungsi saraf sementara. Edema bisa berkurang dalam beberapa jam atau hari dan penderita stroke bisa kembali menggunakan beberapa fungsi tubuhnya.

4. Manifestasi Klinis Stroke Infark Gangguan khusus yang dapat terjadi setelah serangan stroke diantaranya:

a. Hemiparesis dan Hemiplegia

Hemiparesis

(kelemahan) atau hemiplegia (paralisis) pada salah satu bagian tubuh dapat terjadi setelah stroke. Penurunan kemampuan ini biasanya disebabkan oleh infark pada bagian otak yang mengntrol gerakan (saraf motorik) dari korteks bagian depan.

b. Afasia

Afasia adalah penurunan kemampuan berkomunikasi, bisa melibatkan sebagian atau seluruh aspek dari komuniksi seperti berbicara, membaca, menulis, dan memahami pembicaraan.

c. Disartia dan Disfagia

Disartia adalah kondisi artikulasi yang diucapkan tidak sempurna yang menyebabkan kesulitan dalam berbicara. Disfagia adalah ketidakmampuan menelan cairan atau makanan.

d. Perubahan Penglihatan Stroke yang terjadi di bagian lobus parietal atau temporal bisa mengganggu jaringan penglihatan dari saluran optik ke korteks oksipital dan mengganggu ketajaman penglihatan.

e. Hemianopia Homonimus
Hemianopia homonimus (figur 70-4) adalah kehilangan penglihatan pada setengah bagian yang sama dari lapang pandang dari setiap mata. Klien hanya bisa melihat setengah dari penglihatan normal.

f. Sindrom Horner

Sindrom horner adalah paralisis pada saraf simpatis ke mata yang menyebabkan tenggelamnya bola mata, ptosis bagian kelopak mata atas, bagian bawah kelopak mata sedikit terangkat, pupil mengecil, dan air mata berkurang.

g. Agnosia

Agnosia

adalah

gangguan pada kemampuan mengenali benda melalui indra. Tipe yang paling sering adalah agnosia pada indra penglihatan dan indra pendengaran.

h. Negleksi Unilateral

Negleksi unilateral

adalah ketidakmampuan merespon stimulus pada bagian kontralateral dari bagin infark serebral.

i. Penurunan Sensorik

Perubahan sensorik dapat terjadi karena stroke pada jalur sensori dari lobus paritel yang disuplai oleh arteri serebral anterior atau bagian tengah.

j. Inkontinensia

Stroke bisa mengakibatkan disfungsi pada sistem pencernaan dan perkemihan. Salah satu tipe neurologi perkemihan adalah tidak dapat menahan kandung kemih, otak tidak bisa mengartikan pesan dengan tepat sehingga mengakibatkan kondisi sering berkemih dan 
merasa sangat ingin buang air kecil. Terkadang klien juga mengalami kesulitan buang air besar jika terjadi gangguan neurolgi sistem pencernaan.

5. Penatalaksanaan Keperawatan pada Stroke Infark

Pasien stroke idealnya dirawat di unit stroke, peran perawat disini sangat utama sehingga perawat yang bertugas di unit stroke harus memiliki pengetahuan dan keterampilan merawat pasien stroke, yang diperoleh melalui pendidikan khusus yang terprogram dan terstruktur, yang dibuktikan dengan sertifikat. Peran utama perawat dalam tim stroke mencakup peran sebagai pemberi layanan asuhan keperawatan atau provider, pendidik atau educator, penasihat atau consellor bagi pasien dan keluarga, fasilitator, dan peran sebagai peneliti atau researcher. Adapun penatalaksanaan keperawatan pada pasien stroke diantaranya :

a. Melakukan observasi status neurologidan keadaan umum pasien secara ketat, melakukan deteksi dini adanyagangguan menelan dan inkontinensia urin, serta melakukan mobilisasi dinidan stimulasi dini.

b. Mengkaji status fungsi psikososial pasien.

c. Mendeteksi efek samping obat yang mungkin terjadi.

d. Memberikan bantuan dalam memenuhi kebutuhan sehari-hari dan memberikan dukungan terhadap kebutuhan psikologis pasien

e. Memberikan perlindungan untuk mencegah jatuh atau cedera

f. Mencegah/ meminimalkan komplikasi dengan cara melakukan observasi ketat dan melakukan intervensi keperawatan untuk mencegah terjadinya komplikasi akibat immobilisasi, seperti infeksi paru, dekubitus, serta Deep Vein Thrombosis (DVT) yang dapat mengancam jiwa pasien.

g. Memberikan kesempatan dan melatih pasien untuk mandiri

h. Memberi kesempatan kepada pasien dan keluarga untuk berlatih dan beradaptasi dengan kelemahan yang dialami.

i. Memberikan edukasi kepada pasien dan keluarga tentang perawatan pasien stroke di rumah dan membantu pasien untuk beradaptasi dengan pola kehidupan yang baru.

\section{Gangguan Fungsi Menelan pada Pasien Stroke Infark}

Dampak negatif dari stroke dapat mengakibatkan sel neuron mengalami nekrosis atau kematian jaringan, sehingga mengalami gangguan fungsi. Gangguan fungsi yang terjadi tergantung pada besarnya lesi dan lokasi lesi. Pada stroke fase akut, pasien dapat mengalami gangguan menlan atau disfagia. Gangguan menelan pada pasien stroke dapat disebabkan oleh edema otak, menurunnya tingkat kesadaran, ataupun akibat proses diaschisis, yang biasanya bersifat sementara. Tetapi bila lesi terjadi di daerah batang otak, kemungkinan pasien akan mengalami gangguan menelan (disfagia) yang menetap. Lesi pada hemisfer kiri menyebabkan menurunnya aktifitas motorik di oral dan apraxia, sedangkan lesi di hemisfer kanan berhubungan dengan terlambatnya refleks menelan, bolus tertahan difaring, sehingga dapat menyebabkan aspirasi.

Selama fase akut tidak ada hubungannya antara kejadian aspirasi atau gangguan menelan (disfagia) dengan lokasi stroke dan letak lesi. 
Stroke akut pada batang otak kemungkinan dapat menyebabkan disfagia dengan atau defisit neurologik yang lain. Hampir 62,5 pasien stroke batang otak mengalami aspirasi, terutama lesi pada medula atau pons. Risiko aspirasi akan meningkat bila mengenai bilateral, dan biasanya berupa aspirasi yang tersembunyi. Saraf kranial $X$ sampai XII dismobilitas dan asimetris faring, laring tidak menutup sempurna, terkumpulnya bolus di vallecula, dan tidak sempurnanya rileksasi atau spasme dari krikofaringeal. Gangguan menelan bisa terjadi pada fase berikut ini :

\section{Fase Oral}

Kelemahan otot menelan pada fase oral dapat berupa kelemahan otot lidah, buruknya koordinasi bibir, pipi, dan lidah yang menyebabakan terkumpulnya maknan dalam mulut atau masuknya bolus ke faring sebelum menelan yang dapat menyebabkan aspirasi. Gangguan pada fase oral ini juga dapat berupa gangguan inisiasi menelan oleh perubahan status menelan dan kognitif, yang beresiko terjadi pengumpulan bolus makanan di rongga mulut dan resiko terjadi aspirasi.

2. Fase Faringeal

Pada fase ini, dapat terjadi disfungsi palatum dan faring superior yang menyebabkan makanan atau cairan refleks ke nasofaring. Dapat juga terjadi berkurangnya elevasi laring dan faring sehingga meningkatkan resiko aspirasi. Gangguan lainnya terjadi kelemahan otot kostriktor faring yang menyebabkan pengumpulan bolus di valekula dan sinus piriformis yang beresiko terjadi aspirasi, atau dapat juga terjadi gangguan pada otot krikofaring yang akan mengganggu koordiasi prosese menelan.
3. Fase Esofagus

Kelainan yang mungkin terjadi pada fase ini adalah kelainan dinding esofagus atau kelemahan peristaltik esofagus.

\section{Latihan Vokal pada Pasien Stroke Infark}

1. Koordinasi Vokal dengan Saraf di Otak.

Berdasarkan kajian

neurolinguistik, membunyikan suatu huruf melibatkan ratusan saraf. Sarafsaraf tersebut berkoordinasi antara satu dengan yang lain agar dapat menghasilkan bunyi yang akan diucapkan oleh seseorang. Gangguan pada salah satu saraf menyebabkan gangguan terhadap alat ucap. Akibatnya bunyi yang dihasilkan akan cacat atau membuat pendengar kesulitan untuk menafsirkannya. Hal ini disebabkan karena alat-alat ucap tidak dapat berfungsi dengan baik untuk membunyikan suatu fonem, yang bisa membawa perubahan pada bunyi bahasa yang akan diucapkan. Ucapan akan menyimpang dari apa yang seharusnya dibunyikan dan keadaan ini akan sulit dipahami oleh pendengar. Saraf utama yang terlibat dalam menghasilkan ucapan adalah:

a. Saraf kranial ke V (Trigeminus) yang berperan dalam pergerakan mulut dan rahang.

b. Saraf kranial ke X (Vagus) yang beperan dalam otototot pita suara.

c. Saraf kranial ke XII (Hipoglossus) yang berperan dalam pergerakan lidah.

Dari fisiologi otak manusia diketahui bahwa otak memegang peran yang sangat penting dalam bahasa. Apabila input yang masuk adalah dalam bentuk lisan, maka bunyi-bunyi 
itu ditanggapi di lobus temporal, khususnya oleh korteks primer pendengaran.

2. Teknik Latihan Vokal

Teknik latihan vokal dilakukan dengan cara mengucapkan huruf " $\mathrm{A}, \mathrm{I}$, U, E, O" sesering mungkin. Adapun tahapannya seperti berikut :

a. Berdiri di depan cermin (jika kondisi klien memungkinkan)

b. Ucapkan (keluarkan suara) vokal $\mathrm{A}, \mathrm{I}, \mathrm{U}, \mathrm{E}, \mathrm{O}$ dengan suara keras dan lantang.

c. Lakukan sesering mungkin, minimal setiap sebelum makan.

d. Jika bosan dengan cara ini, bisa dengan cara membaca koran atau bernyanyi dengan suara keras.

3. Indikasi Latihan Vokal

Latihan vokal diindikasikan untuk penderita stroke yang mengalami gangguan bicara atau berkomunikasi, serta melatih kemampuan mengunyah dan menelan. Latihan vokal diindikasikan untuk pasien gangguan berekspresi.

4. Indikator Penilaian

Vokal yang baik jika pada saat diucapkan suara yang dihasikan benarbenar berbunyi sasuai. Huruf A benarbenar berbunyi A bukan menjadi HA atau $\mathrm{AH}$, huruf I tidak menjadi $\mathrm{HI}$, huruf $\mathrm{U}$ tidak menjadi $\mathrm{HU}$, dan seterusnya. Jika bunyi yang keluar berbeda saat mengucapkan huruf A, I, U, E, O maka vokal dinyatakan buruk.

5. Prosedur Latihan Vokal

Prosedur latihan vokal untuk klien dalam masa perawatan di rumah sakit adalah sebagai berikut:

a. Jelaskan prosedur yang akan dilakukan.

b. Tempatkan pasien pada posisi fowler atau semi fowler.
c. Anjurkan klien untuk melakukan latihan vokal selama 3-5 menit.
d. Amati pasien selama melakukan latihan vokal.
e. Lakukan kontrak waktu untuk latihan vokal selanjutnya.

\section{Kerangka Pemikiran Penelitian}

\section{Pengaruh Latihan Vokal terhadap Perubahan Kemampuan Menelan pada Pasien Stroke Infark}

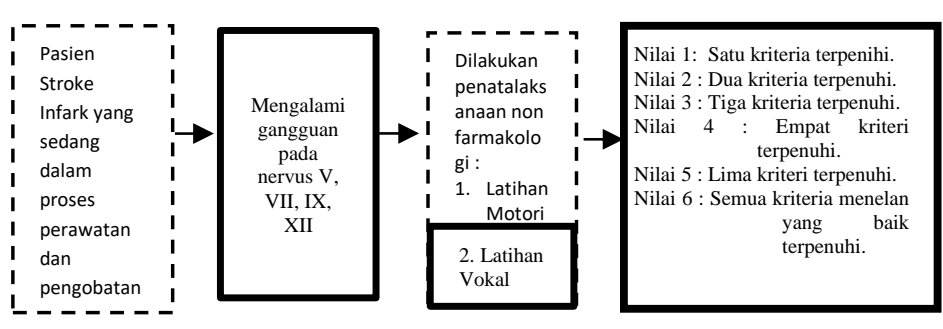

Keterangan :

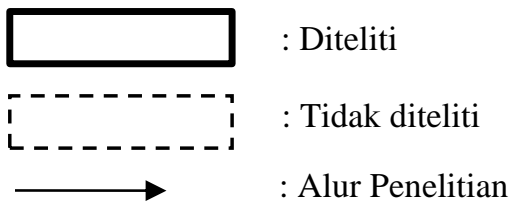

Sumber: Modifikasi dari Muttaqin, Arif. (2008), Crary M.A. Dkk. (2005), Black, Joyce. Hawks, dan Jane. 2014, dan Wardhana, W, A (2011)

\section{METODE PENELITIAN}

Penelitian ini merupakan penelitian kuantitatif dengan menggunakan desain penelitian quasi experiment one group Pre Test and Post Test Design. Populasi target dalam penelitian ini seluruh pasien stroke yang ada di ruang Cempaka RSUD dr. Slamet Garut, sedangkan populasi terjangkaunya pasien stroke infark yang sedang dirawat selama bulan Mei sampai dengan bulan Juni 2015 yang diambil menggunakan teknik purposive sampling sebanyak 10 orang dengan kriteria inklusi sebagai berikut :

1. Pasien stroke infark yang mengalami gangguan menelan 
dengan tingkat kesadaran kompos mentis.

2. Pasien stroke infark yang tidak dipasang alat bantu makan (Nasogastric Tube).

3. Pasien stroke infark yang mampu berkomunikasi (berbicara dan mendengar).

4. Pasien stroke infark yang tidak mengalami paralisis pada otot wajah.

5. Pasien stroke infark yang sedang dirawat mulai dari hari ke 1 sampai dengan hari ke 3 .

6. Bersedia menjadi responden dengan dibuktikan oleh penandatanganan informed consent.

Adapun kriteria ekslusi sampel dalam penelitian ini adalah sebagai berikut :

1. Pasien stroke infark yang mengalami paralisis otot wajah dan tidak mampu membuka atau menutup mulut dengan cepat.

2. Pasien stroke infark yang sedang dalam proses fisioterapi atau speech therapy.

3. Pasien stroke infark yang mengalami afasia.

Instrumen penelitian yang digunakan lembar ceklis observasi berdasarkan panduan terstruktur untuk latihan vokal dan perubahan kemampuan menelan. Pengumpulan data dilakukan setelah latihan vokal pada kelompok intervensi 2 kali setiap hari selama 6 hari dengan durasi 5 menit. Analisa data dilakukan melalui 2 tahap, yaitu:

\section{Analisa Univariat}

Variabel yang dianalisis adalah kemampuan menelan sebelum dilakukan latihan vokal dan kemampuan menelan sesudah dilakukan latihan vokal, parameter yang digunakan adalah nilai mean dan standar deviasi kemampuan menelan. Data diolah dengan menggunakan SPSS versi 16.

\section{Analisis Bivariat}

Hasil uji normalitas menunjukan bahwa, data tidak berdistribusi normal dimana $p$ value pre test 0,03 dan $p$ value post test 0,00 sehingga analisis statistik yang digunakan menggunakan statistik non parametrik dengan uji Wilcoxon.

\section{E. HASIL PENELITIAN}

1. Kemampuan Menelan Pasien Stroke Infark Sebelum Dilakukan Latihan Vokal di Ruang Cempaka RSUD dr. Slamet Garut.

\section{Tabel 1}

Skor Rerata Kemampuan Menelan Pasien Stroke Infark Sebelum

Dilakukan Latihan Vokal di Ruang Cempaka RSUD dr. Slamet Garut Tahun $2015(\mathrm{n}=10)$

\begin{tabular}{lll}
\hline $\begin{array}{c}\text { Kategori } \\
\text { Pengukuran }\end{array}$ & $\begin{array}{l}\text { Nilai } \\
\text { Rata- } \\
\text { Rata }\end{array}$ & $\begin{array}{l}\text { St. } \\
\text { Deviasi }\end{array}$ \\
\hline $\begin{array}{l}\text { Sebelum } \\
\text { Dilakukan }\end{array}$ & 3,00 & .816 \\
Latihan Vokal & & \\
\hline
\end{tabular}

Berdasarkan tabel 1 diatas nilai rata-rata kemampuan menelan pasien stroke infark sebelum dilakukan latihan vokal sebesar 3,00 dengan standar deviasi 0,816 .

2. Kemampuan Menelan Pasien Stroke Infark Setelah Dilakukan Latihan Vokal di Ruang Cempaka RSUD dr. Slamet Garut.

Tabel 2

Skor Rerata Kemampuan Menelan Pasien Stroke Infark Setelah Dilakukan 
Latihan Vokal di Ruang Cempaka

RSUD dr. Slamet Garut Tahun 2015 $(\mathrm{n}=10)$

\begin{tabular}{lll}
\hline $\begin{array}{l}\text { Kategori } \\
\text { Pengukuran }\end{array}$ & $\begin{array}{l}\text { Nilai } \\
\text { Rata- } \\
\text { Rata }\end{array}$ & $\begin{array}{l}\text { St. } \\
\text { Deviasi }\end{array}$ \\
\hline Setelah & 5,50 & .527 \\
Dilakukan & & \\
Latihan Vokal & & \\
\hline
\end{tabular}

Berdasarkan tabel 2 diatas, nilai rata-rata kemampuan menelan sesudah dilakukan latihan vokal sebesar 5,50 dengan standar deviasi 0,527.

3. Pengaruh Latihan Vokal terhadap Perubahan

Kemampuan Menelan pada Pasien Stroke Infark di Ruang Cempaka RSUD dr. Slamet Garut

\section{Tabel 3}

Pengaruh Latihan Vokal terhadap Perubahan Kemampuan Menelan pada Pasien Stroke Infarkdi Ruang Cempaka RSUD dr. Slamet Garut $(n=20)$

\begin{tabular}{|c|c|c|c|}
\hline $\begin{array}{l}\text { Kategori } \\
\text { Pengukuran }\end{array}$ & $\begin{array}{l}\text { Nilai } \\
\text { Rata }\end{array}$ & Rata- & $\begin{array}{l}p- \\
\text { valu } \\
e\end{array}$ \\
\hline $\begin{array}{l}\text { Sebelum Dilakukan } \\
\text { Latihan Vokal }\end{array}$ & 6.75 & & $\begin{array}{l}0,00 \\
4\end{array}$ \\
\hline $\begin{array}{l}\text { Setelah Dilakukan } \\
\text { Latihan Vokal }\end{array}$ & 14.25 & & \\
\hline
\end{tabular}

Berdasarkan tabel 3 diatas, hasil uji bivariat dengan menggunakan uji Wilcoxon diperoleh nilai p 0,004. Hal ini yang mempunyai makna, terdapat pengaruh latihan vokal terhadap perubahan kemampuan menelan pada pasien stroke infark dengan perubahan skor rata-rata sebesar 7,5 dari sebelum dilakukan dengan setelah dilakukan latihan vokal. Dari data tersebut dapat diketahui kemampuan menelan pada pasien stroke infark memiliki kecenderungan meningkat (lebih baik) setelah dilakukan latihan vokal.

\section{F. PEMBAHASAN}

1. Kemampuan Menelan Pasien Stroke Infark Sebelum Dilakukan Latihan Vokal di Ruang Cempaka RSUD dr. Slamet Garut

Hasil penelitian nilai rata-rata kemampuan menelan pasien stroke infark sebelum dilakukan latihan vokal adalah sebesar 3,00 dengan standar deviasi 0,816. Data ini merupakan data awal sebagai dasar untuk mengetahui ada atau tidaknya perubahan skor setelah nanti dilakukan latihan vokal. Salah satu komplikasi yang dapat ditimbulkan dari stroke infark adalah gangguan fungsi menelan yang dapat beresiko terjadinya aspirasi oleh makanan ke saluran pernafasan. Tejadinya stroke akut dapat menyebabkan disfagia dengan atau defisit neurologik yang lain. Hampir 62,5 pasien stroke batang otak mengalami aspirasi. Risiko aspirasi akan meningkat bila terjadinya sumbatan / infark mengenai kedua bagian otak (bilateral) yang berdampak pada saraf kranial X sampai XII yang dapat mengakibatkan dismobilitas dan asimetris faring, laring tidak menutup sempurna, dan terkumpulnya bolus di vallecula, akibat spasme daerah krikofaringeal. Latihan vokal diindikasikan untuk penderita stroke yang mengalami gangguan bicara atau berkomunikasi, serta melatih kemampuan mengunyah dan menelan.

2. Kemampuan Menelan Pasien Stroke Infark Setelah Dilakukan Latihan Vokal di Ruang Cempaka RSUD dr. Slamet Garut

Hasil penelitian nilai rata-rata kemampuan menelan pasien stroke infark setelah dilakukan latihan vokal sebesar 5,50 dengan standar deviasi 
0,527. Berdasarkan data ini, terdapat perubahan nilai rata-rata antara sebelum dilakukan latihan vokal dengan setelah dilakukan latihan vokal yaitu sebesar 2,5. Berdasarkan hasil penelitian tersebut kemampuan menelan pada pasien stroke infark memiliki kecenderungan meningkat setelah dilakukan latihan vokal. Terjadinya peningkatan kemampuan menelan pada pasien stroke infark disebabkan oleh beberapa faktor, salah satunya latihan motorik pada daerah otot-otot wajah dan lidah yang dipersarafi oleh saraf kranial V, VII, X, dan XII.

Latihan motorik yang dilakukan saat latihan vokal dapat menghasilkan tekanan yang memberikan stimulus pada batang otak sebagai respon sensori, kemudian respon dikirim melalui saraf-saraf kranial yang berperan untuk mengatur aktifitas otototot mengunyah dan menelan. Fungsi menelan yang terganggu akibat kelemahan otot dapat kembali berfungsi jika dilakukan latihan secara rutin. Hal ini dikarenakan proses menelan memerlukan beberapa elemen input sensori dari saraf kranial, koordinasi saraf pusat, dan respon mtorik sebagai umpan balik.

3. Pengaruh Latihan Vokal terhadap Perubahan Kemampuan Menelan pada Pasien Stroke Infark di Ruang Cempaka RSUD dr. Slamet Garut

Hasil uji bivariat dengan uji Wilcoxon diperoleh nilai p 0,004 yang mempunyai makna bahwa terdapat pengaruh latihan vokal terhadap perubahan kemampuan menelan pada pasien stroke infark. Hal ini yang mempunyai makna, terdapat pengaruh latihan vokal terhadap perubahan kemampuan menelan pada pasien stroke infark dengan perubahan skor rata-rata sebesar 7,5 dari sebelum dilakukan dengan setelah dilakukan latihan vokal. Dari data tersebut dapat diketahui kemampuan menelan pada pasien stroke infark memiliki kecenderungan meningkat (lebih baik) setelah dilakukan latihan vokal.

$$
\text { Upaya meningkatkan }
$$

kemampuan menelan pada pasien stroke infark salah satunya dapat dilakukan dengan melakukan latihan motorik untuk melatih kekuatan otot yang berperan dalam proses mengunyah dan menelan. Latihan motorik dapat memperbaiki status fungsi menelan ${ }^{7}$. Berdasarkan kajian neurolinguistik mengungkapkan bahwa tindakan membunyikan suatu huruf dapat melibatkan fungsi ratusan saraf didalam otak, dimana saraf utama yang terlibat pada proses ini adalah saraf kranial ke V (Trigeminus), ke $\mathrm{X}$ (Vagus) dan saraf ke XII (Hipoglossus).

Latihan motorik pada otot otot wajah dan lidah tersebut salah satunya dapat dilakukan melalui latihan vokal dengan menyebutkan huruf A, I, U, E, O. Latihan vokal berpengaruh pada proses menelan karena kontrol persarafan pada proses menelan melibatkan saraf kranial ke V, VII, IX, X, dan XII yang juga berfungsi saat proses berbicara. Latihan vokal dapat mengoptimalkan kemampuan saraf-saraf yang mengalami penurunan fungsi menjadi berfungsi kembali dengan baik. Selain itu, latihan vokal merupakan salah satu teknik rehabilitasi fisik bagi klien pasca stroke infark, hal ini bertujuan untuk memanfaatkan dan meningkatkan kemampuan fungsi tubuh yang masih baik salah satunya fungsi dalam menelan makanan dan minuman. Fungsi menelan yang baik dapat memudahkan makanan dan cairan masuk ke dalam tubuh sehingga 
nutrisi yang dibutuhkan oleh tubuh dapat terpenuhi.

\section{G. KESIMPULAN DAN SARAN}

Simpulan penelitian ini adalah kemampuan menelan pasien stroke infark memiliki kecenderungan meningkat (lebih baik) setelah dilakukan latihan vokal. Selain itu, terdapat pengaruh latihan vokal terhadap perubahan kemampuan menelan pada pada pasien stroke infark di ruang Cempaka Rumah Sakit Umum Daerah dr. Slamet Garut Tahun 2015.

1. Bagi Rumah Sakit Hasil penelitian ini dapat dijadikan sebagai bahan referensi dan pertimbangan bagi dokter dan perawat dalam menangani pasien stroke infark yang mengalami gangguan fungsi menelan dengan cara melakukan latihan vokal.

2. Bagi Peneliti Selanjutnya

Disarankan untuk melakukan penelitian yang lebih kompleks tentang latihan vokal terhadap kemampuan menelan dengan melibatkan disiplin ilmu kesehatan yang lain khususnya unit rehabilitasi medik dalam menentukan tindakan pelayanan kesehatan yang optimal dalam menangani gangguan fungsi menelan pada pasien stroke infark.

\section{DAFTAR PUSTAKA}

Departemen Kesehatan RI. 2014. Laporan Hasil Riset Kesehatan Dasar Indonesia (Riskesdas) 2013. Diakses Melalui http://www.Depkes.go.id pada tanggal 11 November 2015.

Dinas Kesehatan Kabupaten Garut. 2015. Profil Kesehatan Kabupaten Garut Tahun 2014.

Muttaqin, Arif. 2008. Asuhan Keperawatan Klien dengan Gangguan Sistem Persarafan. Jakarta. Salemba
Medika.

Price, Sylvia A. Wilson, Lorraine M. 2014. Patofisiolofi Konsep Klinik Proses-Proses Penyakit Edisi 6. Jakarta: EGC.

Wardhana, Wisnu. 2011. Strategi Mengatasi dan Bangkit dari Stroke. Yogyakarta. Pustaka pelajar.

Lutfie, Syarief. 2012. Kembali Aktif Pasca Stroke. Solo Metagraf. PT Tiga Serangkai Pustaka Mandiri.

Mulyatsih, MG. Enny. 2009. The Effect of Swallowing Therapy to Swallowing Functional States of Stroke Patients with Dysphagia on The Nursing Context in RSUPN Dr Cipto Mangunkusumo and RSUP Fatmawati Jakarta. Jurnal Keperawatan Indonesia No. 104. Vol II. Halaman 55-62.

Wijaya, Andre Saferi dan Putri, Yassie Mariza. 2013. KMB 2 Keperawatan Medikal Bedah. Yogyakarta. Nuha Medika.

Black, Joyce. Hawks, dan Jane. 2014. Keperawatan Medikal Bedah Manajemen Klinis untuk Hasil yang Diharapkan, Edisi 8. Singapura: Elsevier.

Mansjoer, Arif. Dkk. 2009. Kapita Selekta Kedokteran Edisi Ketiga. Jakarta: Media Aesculapius Fakultas Kedokteran UI.

Weiner, Howard L. 2000. Buku Saku Neurologi. Jakarta. EGC.

Martono, H. dan Kuswardhani, R.A.T. 2009. Stroke dan Penatalaksanaannya oleh Internis. Jakarta: Internal Publishing. Diakses melalui http://download.portalgaruda.org 1 article.STROKE pada tanggal 21 Februari 2015.

Sastra, Gusdi. 2011. Neurolinguistik suatu pengantar. Bandung. 
Alfabeta.

Crary M.A. Dkk. 2005. Initial Psychometric Assessment of a Functional Oral Intake Scale for Dysphagia in Stroke Patients.

Tortora, J. T. Grabowski, S.R. 2000. Principles of Anatomy and Physiology. Toronto. John Wiley \& Sons, Inc. 